\title{
DOAÇÃO DE ORGÃOS POST MORTEM E POLÍTICAS PÚBLICAS NO BRASIL: PONDERAÇÕES CONSTITUCIONAIS ENTRE AS LEIS N.
}

\author{
9.434/97 E 10.211/2001 \\ POST MORTEM ORGAN DONATION AND PUBLIC POLICIES IN BRAZIL: \\ CONSTITUTIONAL WEIGHTS BETWEEN LAWS NO. 9.434/97 AND 10.211/2001 \\ Recebido em 09/11/2017 \\ Aprovado em 16/03/2018 \\ MARCELO BIDOIA DOS SANTOS1 \\ ANTÔNIO LUIS DE OLIVEIRA²
}

RESUMO: Trata-se de investigação qualitativa a revisitar a problemática da doação de órgãos post mortem no Brasil, trazida com a inversão do sistema de consentimento presumido, ocorrida com a Lei n. 10.211/2001, que alterou o Art. $4^{\circ}$ da Lei n. 9.434/97. Essa mudança conferiu à família do falecido a decisão final sobre a doação, fundada no direito de personalidade - o que, paradoxalmente, pode contrariar a decisão do falecido em ceder seus restos mortais para fins altruísticos. Em contrapartida, há preocupação ética e legal no consentimento presumido que assume o corpo humano como res communitatis - apesar de coadunar-se com o princípio da solidariedade a orientar o Estado [Social] na concretização dos direitos à saúde e à vida. Este trabalho parte da hipótese de que a liberalidade familiar de escolha na doação de órgãos post mortem não poderia suplantar a autonomia do individuo que registra seu desejo de ser doador. Ademais, acredita-se, essa possibilidade poderia aumentar, ainda que virtualmente, o potencial de eficiência das políticas públicas de doação post mortem no Brasil - o que justifica essa investigação. Destarte, adotou-se como método de abordagem o método dialético e como técnica de pesquisa a documentação indireta legal e bibliográfica, buscando uma normatização (estática e exegética) que conferisse maior eficiência aos direitos à saúde e à vida, concretizados mediante políticas públicas de doação post mortem, nos moldes constitucionais de um Estado Democrático de Direito - marco teórico. Concluiu-se que a liberalidade familiar só deve dar-se subsidiariamente, se ausente a manifestação registrada do falecido em fazer-se doador.

PALAVRAS CHAVE: Decisão familiar; autodeterminação; Estado Democrático de Direito; solidariedade; direito de personalidade.

ABSTRACT: This qualitative research aims to review the problem of post-mortem organs donation in Brazil, brought with the inversion of presumed consent system, occurred with Law no. 10.211/2001, which amended Article 4 of Law no. 9.434/97. This change gave the deceased's family the final decision on donation, based on personality's rights - which, paradoxically, may contradict the decision taken by the deceased to grant his mortal remains for altruistic purposes. Besides, there is an ethical and legal concern regarding to the presumed consent of the human body as a res communitatis - despite being in line with the principle of solidarity to guide the [Social] State in the concretization of the rights to health and to life. This work starts from the hypothesis that the family liberty of choice in donation of post-mortem organs could not supplant the autonomy of the individual who registers his desire to be a donor. In addition, it is believed that this possibility could increase, albeit virtually, the efficiency potential of post mortem donation public policies in Brazil - which justifies this investigation. Thus, as a method of approach the dialectical method was adopted and as a research technique the legal and bibliographic indirect documentation, seeking a normatization (static and exegetical) that confer greater efficiency to the rights to health and life, materialized through public policies of post mortem donation, within constitutional molds of a Democratic Rule of Law - the theoretical framework. It was concluded that family liberality should only be given subsidiarily, if absent the deceased's registered manifestation of donation.

KEYWORDS: Family decision; self-determination; Democratic State; solidarity; personality rights.

\footnotetext{
1 Advogado. Mestre em Direito pela Faculdade de Direito de Ribeirão Preto - Universidade de São Paulo (FDRP-USP)
}

2 Advogado. Mestrando em Direito pela Faculdade de Direito de Ribeirão Preto - Universidade de São Paulo (FDRP-USP). LLm em Direitos Humanos. 


\section{INTRODUÇÃO}

O Brasil possui o maior sistema público de transplante de órgãos, tecidos e partes do corpo do mundo, realizando mais de 20 mil transplantes por ano. Não obstante, o número de carências cresce, impulsionado por inúmeros casos de possíveis doadores não aproveitados por conta da ausência de concordância familiar, quaisquer sejam suas razões.

Segundo a legislação atual, Lei n. ${ }^{o}$ 9.434/97, eventual remoção de material humano aproveitável para doação está condicionada à anuência da família (como sucedânea dos direitos de personalidade), depois de constatada a morte encefálica. Essa regra independe inclusive da vontade do próprio doador, ainda que manifestada em vida, que pode acabar contrariada pela decisão familiar. Tal sistemática foi dada através da Lei n. ${ }^{\circ}$ 10.211/2001, que inverteu o paradigma original contido na Lei $n^{\circ} 9.434 / 97$, cujo dispositivo trazia a presunção tácita de doação post mortem, excetuada em caso de oposição manifestada pelo doador.

Pois bem. A doação de órgãos constitui parte das políticas públicas que visam dar efetividade aos direitos à vida e à saúde (conforme se percebe da interpretação conjunta dos Artigos 196 e 199, § 4º, ambos da Constituição Federal - CF/88). Como direito social que é (Art. $6^{\circ}$, da $\mathrm{CF} / 88$ ), o direito à saúde deve ser promovido pelo Estado, em sua função (ou, por seu setor) de Estado Social, embasado pelos princípios da igualdade e solidariedade.

A efetivação desses direitos sociais importa, para o Estado, no cumprimento de prestações materiais e jurídicas, mediante a elaboração de normas penais, de organização e procedimento. Essas normas, ao estruturar administrativamente as políticas públicas, devem ser eficientes (Art. 37, da CF/88), maximizando os resultados esperados segundo uma lógica de custo/benefício. Entretanto, referida busca encontra limites de atuação impostos pelo Estado Democrático de Direito, cujos parâmetros impõem conciliar ao máximo os direitos fundamentais em sua completude, i.e., entre os direitos individuais, sociais e coletivos.

Neste trabalho, parte-se da hipótese de que a liberalidade familiar de escolha na doação de órgãos não poderia suplantar a autonomia do individuo que registra seu desejo de ser doador. Esse seria um meio termo condizente com um Estado que se propõe a concretizar direitos fundamentais em todas as suas dimensões. Além disso, acredita-se, essa possibilidade também teria o condão de aumentar, ainda que virtualmente, o potencial de eficiência das políticas públicas de doação de órgãos e material humano no Brasil, resolvendo problemas de 
ordem grave que implicam diretamente no mais fundamental dos direitos do cidadão: sua vida e sua saúde - preocupação que justifica essa investigação.

Dessarte, o presente artigo propõe-se a revisitar a discussão da doação de órgãos post mortem sob um prisma Constitucional qualitativo, adotando como método de abordagem o método dialético e como técnica de pesquisa a documentação indireta legal e bibliográfica, buscando uma normatização (estática e exegética) que confira, ao menos em tese, maior eficiência aos direitos à saúde e à vida a serem concretizados mediante elaboração de políticas públicas de doação de órgãos, mas dentro das regras do Estado Democrático de Direito marco teórico para a investigação, entendido como aquele que concilia, entre outras coisas, os direitos fundamentais individuais, sociais e coletivos (as três gerações de direitos humanos).

Para tanto, o primeiro capítulo aborda as noções centrais de política pública e a concretização dos direitos fundamentais à vida e à saúde no Brasil, em sua relação constitucional com a doação de órgãos post mortem. O segundo capítulo busca reconstruir, de forma breve, a história normativa dessa modalidade de doação de órgãos no país, desde sua primeira legislação até a edição da Lei n. ${ }^{\circ}$ 9.434/97, sob a égide da Constituição Federal de 1988, comparando entre elas as diferentes tratativas legais. O terceiro capítulo analisa o atual estado da política de doação de órgãos post-mortem nacional, dada pela Lei n. ${ }^{\circ}$ 10.211/2001, que modificou a Lei n. 9.434/97, apontando e criticando as principais modificações ocorridas. Por fim, o último capítulo tentou ponderar os argumentos relacionados com a liberalidade familiar na decisão de doação post mortem, a autonomia de vontade do indivíduo doador e os preceitos constitucionais de solidariedade que sustentam o sistema de doação presumida. Por conclusão restou que a liberalidade familiar só deve dar-se subsidiariamente, no caso de ausência, por parte do falecido, de manifestação expressa e registrada em fazer-se doador.

\section{O DIREITO À VIDA E À SAÚdE NAS POLÍTICAS PÚBLICAS DE DOAÇÃO DE ÓRGÃOS BRASILEIRAS}

Por conta de sua interdisciplinariedade e caráter holístico, não há definição única, amplamente aceita sobre política pública, apesar da conhecida ideia de Laswell (1950) que remete o conceito às respostas das perguntas [acerca das decisões e análises políticas]: quem 
ganha o quê, por quê, e o que faz a diferença. Não obstante, Maria Paula Dallari Bucci traz uma conceituação interessante, adequada ao entendimento do tema ora proposto, para quem:

Política Pública é o programa de ação governamental que resulta de um processo ou conjunto de processos juridicamente regulados - processo eleitoral, processo de planejamento, processo de governo processo orçamentário, processo legislativo, processo administrativo processo judicial - visando coordenar os meios à disposição do Estado e as atividades privadas para realização dos objetivos socialmente relevantes e politicamente determinados. (2006, p. 39).

Assim, o estabelecimento de políticas públicas passa, para além de outros critérios (como o econômico), por uma fase de normatização que estabelece seus alcances, objetivos e modos de atuação. Desse modo, sua estrutura deve objetivar a concretização plena da cidadania (SMANIO, 2015, p. 4), acompanhando os ditames de um Estado Democrático de Direito (consagrado no Brasil pelo Art. $1^{\circ}$, caput, da CF/88) em sua evolução. Isso porque, na medida em que o exercício do poder se transforma em nome da proteção da dignidade humana e da cidadania plena, a dimensão política e jurídica se combinam administrativamente no interior do aparelho do Estado: “[...] a política imbricada com a técnica, a gestão pública institucionalizada e regrada pelo direito. A face política do governo vai se revestindo cada vez mais de uma tecitura jurídica" (BUCCI, 2013, p. 34).

Nesse contexto, em que a política é emoldurada pelo direito e manifestada administrativamente, há de se recordar um dos princípios basilares do direito administrativo: aquele que impõe a eficiência à administração pública (Art. 37, caput, da Constituição Federal). ${ }^{3}$ Mas se a administração está adstrita ao direito, posto que inserida em um Estado de Direito, então a própria normatização que servirá como paradigma para a elaboração e desenvolvimento das políticas públicas (i.e., para sua organização, em sentido amplo) deve almejar um conteúdo que se coadune com a eficiência esperada pelo interesse coletivo. Isso porque "[...] o ideal de eficiência, como elemento da boa administração, representa a formalização jurídica de um interesse público geral definido politicamente e que é retroalimentado pela existência de uma estrutura pública organizacional”, de modo que a

\footnotetext{
3 Aqui, vale a pena distinguir a comum confusão realizada entre eficiência e eficácia. Para esta última importa a realização dos objetivos por determinada ação do Estado, não interessando os meios utilizados para tanto. Assim, o Estado pode ser eficaz em resolver determinado problema, não obstante possa fazê-lo com mais recursos do que necessitaria. Já na esfera da eficiência subsiste a preocupação com os mecanismos utilizados para lograr êxito na atividade estatal. Desse modo, busca-se os meios mais econômicos e viáveis, maximizando os resultados e minimizando os custos. Trata-se de relação de custo/benefício: isto é, de se atingir os objetivos pela maneira menos onerosa e mais vantajosa possível. (TORRES, Marcelo Douglas de Figueiredo. Estado, democracia e administração pública no Brasil. Rio de Janeiro: Fundação Getúlio Vargas, 2004. p. 175).
} 
eficiência “[...] também no tocante específico da 'organização' administrativa faz-se presente, ou seja, no aspecto estático, de estruturação legal” (GABARDO, 2012, pp. 343-343).

Significa dizer que uma melhor estruturação legal-administrativa tem o poder, ao menos em tese e dentro dessa lógica de eficiência enquanto relação custo/benefício, de melhorar os resultados almejados pelas políticas públicas sem despender mais recursos ou alterar substantivamente suas ações para isso.

Pois bem, são políticas públicas que concretizam os direitos fundamentais à saúde e à vida enquanto direitos sociais (também conhecidos como direitos humanos ou fundamentais de segunda geração ou dimensão) - e, do mesmo modo, são esses direitos que fundamentam a existência das políticas públicas de doação de órgãos post-mortem no país.

Os direitos de segunda geração correspondem aos direitos sociais, econômicos e culturais, concretizados mediante a atuação do Estado Social (ou de bem-estar social), que é fruto das lutas operárias de inspirações socialistas, surgidas nas sociedades industriais do século XIX (MARMELSTEIN, 2016, pp. 46-48) em meio ao nascimento da questão social. Trata-se de direitos que dizem respeito à assistência social, saúde, educação, trabalho, etc. Sua maior característica é a imposição ao Estado de um dever de intervir na esfera social e econômica para prover bem-estar aos cidadãos, como um modo de estabelecer a justiça social e dar condições reais de oportunidades a todos - uma igualdade material, para além da mera igualdade formal entre os homens perante a lei (SARLET, 2012, pp. 47-48).

Assim, os direitos de segunda dimensão cumprem uma função de direito a prestação (material e jurídica), ${ }^{4}$ veiculados mediante normas constitucionais de eficácia limitada de princípio programático, que norteiam e condicionam a legislação infraconstitucional futura, a ser editada pelo legislador para complementar o comando constitucional. 5

\footnotetext{
${ }^{4}$ A maior característica dos direitos a prestação está na exigência de uma ação positiva por parte do Estado, e não de uma omissão, como no caso dos direitos de defesa, correspondendo a uma obrigação jurídica de fazer ou de dar. Tais prestações podem ser divididas em prestação material, a qual se refere à concretização de direitos sociais fundamentais de forma fática e material, sujeitas às condições momentâneas da riqueza nacional (reserva do possivel); e prestação jurídica, para qual o objeto do direito será a normação pelo Estado do bem protegido como fundamental. Essa prestação pode dar-se pela emissão de normas jurídicas penais ou normas de organização e de procedimento. (MENDES, Gilmar Ferreira. BRANCO, Paulo Gustavo Gonet. Curso de Direito Constitucional. $6^{\text {a }}$ Ed. Rev. e Atual. São Paulo: Saraiva, 2011. pp. 180-183).
}

5 Normas constitucionais programáticas são aquelas em que o constituinte limitou-se a traçar princípios a serem cumpridos pelos órgãos (legislativos, executivos, judiciários e administrativos), enquanto diretrizes a serem seguidas em suas respectivas atividades, objetivando os fins sociais do Estado. (SILVA, José Afonso. Aplicabilidade das Normas Constitucionais. $8^{\mathrm{a}}$ Ed. São Paulo: Editora Malheiros, 2012. p. 135). 
No ordenamento jurídico pátrio, o direito à vida encontra-se consagrado no capítulo Dos Direitos Individuais, especificamente no Art. $5^{\circ}$, caput, da Carta Magna, constituindo o primeiro valor básico da lista que inspira todos os outros direitos fundamentais, pressupostos da dignidade humana. Nesse sentido, o direito à vida se refere primeiro ao direito do cidadão de ter sua vida assegurada, garantida contra arbitrariedades ou interferências por parte do Estado, desempenhando função de direito de defesa - não por menos, tal motivação levou à proibição da Pena de Morte, uma garantia fundamental à vida (SILVA, 2013, pp. 203-204).

Sem embargo, o direito à vida não pode ser apenas encarado do ponto de vista defensivo em relação à integridade física do ser humano. Ao contrário, também o direito à vida se relaciona com uma postura ativa do Estado na tentativa de garanti-lo dignamente, 6 pressupondo uma intervenção estatal positiva na esfera socioeconômica - típica do rol de direitos sociais. É nesse passo que sua efetivação se dá a partir de políticas públicas, intrinsicamente ligadas ao direito fundamental social à saúde (previsto no Art. $6^{\circ}$, da CF/88).

No Brasil, foi a Constituição de 1934 que inaugurou o Estado Social, aspirando em seu preâmbulo por "justiça e bem-estar social e econômico" (BRASIL, 1934). Mas somente a Constituição de 1988 consagrou o direito fundamental de proteção à saúde (MENDES; BRANCO; 2011, p. 685), dentro de um sistema integrado de seguridade social.

Conforme dispõe o Art. 194, da Carta Magna: “A seguridade social compreende um conjunto integrado de ações de iniciativa dos Poderes Públicos e da sociedade, destinadas a assegurar os direitos relativos à saúde, à previdência e à assistência social” (BRASIL, 1988). Por sua vez, o Art. 196 informa que o direito social à saúde, direito de todos e dever do Estado, deve ser efetivado mediante políticas públicas (sociais e econômicas).

Assim, o direito à saúde se qualifica como um direito social por excelência, cumprindo função de direito à prestação em sentido estrito - i.e., direito ao tratamento em hospitais e a medicamentos -; como à prestação em sentido amplo, tal qual o direito à edição de leis que regulamentam o Sistema Único de Saúde (OLSEN, 2008, p. 56). Trata-se de um dever do Estado a ser efetivado mediante políticas públicas (ou seja, não se trata de um direito absoluto

\footnotetext{
${ }^{6}$ Desta maneira, o direito à vida cumpre dupla função: primeiro a de direito de defesa; mas também a de direito à prestação enquanto direito que demanda do Estado um dever positivo de fornecer medicamentos indispensáveis à sobrevivência do enfermo (Cf. RE-AgR 271.286, Min. Rel. Celso de Mello, DJ de 24-11-2000). Mais do que isso, o direito à vida também deve ser entendido de modo mais amplo, a preservar, para além da existência física, a vida digna. Nesse sentido, pode ensejar ainda outras pretensões, como aquelas referentes à habitação, alimentação e etc. (MENDES, Gilmar Ferreira. BRANCO, Paulo Gustavo Gonet. Curso de Direito Constitucional. $6^{a}$ Ed. Rev. e Atual. São Paulo: Saraiva, 2011. pp. 292-294).
} 
a qualquer procedimento necessário, mas de um direito público subjetivo a políticas públicas que promovam, protejam e recuperem a saúde) em dimensão individual ou coletiva:

Numa visão geral, o direito de proteção à saúde há de se efetivar mediante ações específicas (dimensão individual) e mediante amplas políticas públicas que visem à redução do risco de doença e de outros agravos (dimensão coletiva). Nessas perspectivas, as pretensões formuladas e formuláveis tanto poderão dizer respeito a atos concretos como a políticas e ações administrativas que contribuam para a melhoria do sistema de saúde, incluídas aqui as normas de organização e procedimento (MENDES; BRANCO; 2011, p. 688).

Nesse contexto, quanto à doação de órgãos, deixou o constituinte uma norma constitucional de eficácia limitada, que impôs ao legislador ordinário a tarefa de facilitar a remoção de órgãos para fins de transplante, traçando para isso alguns parâmetros:

Art. 199, $\S 4^{\circ}$ : a lei disporá sobre as condições e os requisitos que facilitem a remoção de órgãos, tecidos e substâncias humanas para fins de transplante, pesquisa e tratamento, bem como a coleta, processamento e transfusão de sangue e seus derivados, sendo vedado todo tipo de comercialização (BRASIL, 1988).

A normatização referida pela Constituição é dada hoje pela Lei 9.434/97, tendo já sofrido alterações pela Lei 10.211/2001 e Lei 11.521/2007. Mas antes de se aprofundar no tema proposto, a respeito da vontade do doador post mortem e a eficácia das políticas públicas de doação de órgãos, far-se-á um rápido retrospecto desse instituto nas legislações brasileiras.

\section{UMA BREVE RECONSTRUÇÃO HISTÓRICO-NORMATIVA DA DOAÇÃO DE ÓRGÃOS POST MORTEM NO BRASIL}

A doação post-mortem é aquela realizada após a morte do doador, "precedida de diagnóstico de morte encefálica constatada e registrada por dois médicos não participantes das equipes de remoção e transplante, mediante a utilização de critérios clínicos e tecnológicos definidos por resolução do Conselho Federal de Medicina" - Art. $3^{\circ}$, da Lei 9.434/97. A autorização para a realização desse procedimento, hoje, depende do consentimento familiar do de cujus. Mas nem sempre foi assim nos anais da legislação brasileira de doação de órgãos.

No Brasil, a história legislativa sobre os transplantes é relativamente curta, sendo definida por cinco momentos históricos. De forma geral, o Estado iniciou seu controle sobre 
as doações de forma conservadora, condescendente com o pouco entendimento que havia sobre o tema, buscando respeitar a mentalidade coletiva de então.

Em 1.963 foi instituída a primeira Lei sobre o tema. A Lei $n^{\circ} 4.280$ dispunha sobre a "extirpação de órgãos ou tecidos de pessoa falecida para fins de transplante", tratando seu conteúdo de forma muito simples e incompleta. Tratava apenas da doação post mortem, não disciplinando as doações entre vivos. A lei autorizava apenas a extirpação de córneas, artérias e ossos, exigindo-se três formas de manifestação da vontade para doar, conforme seu Art. $1^{\text {o: }}$ a primeira, a manifestação positiva escrita do titular em vida; ou a segunda - não oposição do cônjuge ou parentes até o segundo grau; ou então o consentimento das corporações religiosas ou civis das quais o de cujus fazia parte e que seriam responsáveis pelo destino dos despojos (BRASIL, 1963).

Posteriormente sobreveio a Lei $n^{0} 5.479 / 68$, revogando a lei anterior. Esta lei inovou a legislação sobre doação de órgãos e tecidos, regulando para além da retirada de tecidos, órgãos e partes do cadáver, os casos de doações entre vivos. Quanto à doação post mortem, manteve a necessidade de prova incontestável do óbito, e de autorização expressa do doador, complementando, no que concerne a possíveis doadores, os menores e os incapazes.

Quanto ao consentimento para a doação, o novo texto legal determinou em seu Art. $3^{\circ}$ que a permissão para a retirada de órgãos e partes do cadáver dar-se-ia nos casos de: I) autorização expressa do disponente; II) pela manifestação da vontade, através de instrumento público, quando se tratasse de dispoentes relativamente incapazes ou menores; III) pela autorização escrita do cônjuge, não separado, e sucessivamente, de descendentes, ascendentes e colaterais, ou das corporações religiosas ou civis responsáveis pelo destino dos despojos; IV) na falta de responsáveis pelo cadáver, a retirada de órgãos somente poderia se dar com a autorização do diretor da instituição onde ocorresse o óbito, desde que preenchido os demais requisitos legais. Ressalte-se que essa lei nunca foi regulamentada pelo Poder Executivo, apesar da determinação legal estabelecendo prazo de 60 dias - Art. 15 (BRASIL, 1968).

A despeito da edição da Lei $n^{0} 5.479 / 68$, restou ineficaz a aplicação deste diploma em proporcionar um aumento relevante na oferta de órgãos doados. Assim, diante da "falta" de material orgânico a ser transplantado, criou-se na década de 1980 a oferta mercadológica em relação ao corpo humano, como resultado da relação entre o refinamento das técnicas médicas e o aumento da demanda por material orgânico (BERLINGUER; GARRAFA, 2001). 
Tendo em vista essa questão, o constituinte de 1988 optou por vedar qualquer tipo de mercancia no que se refere aos transplantes de material humano, conforme visto no Art. 199, $\S 4^{\mathrm{o}}$, da Constituição Federal, fundamentando-se na dignidade da pessoa humana (LIMA, 2012, p.175), mas nada dispôs sobre consentimento do doador. Restou à lei infraconstitucional o papel de regulamentar as condições e requisitos que facilitassem a remoção de órgãos, tecidos e substâncias. Foi assim que, para dar efetividade a este preceito constitucional, nasceu a Lei n. 8.489/92.

A Lei $\mathrm{n}^{\mathrm{o}} 8.489 / 92$ disciplinou a retirada de órgãos e tecidos de cadáveres e para fins terapêuticos, científicos e humanitários, exigindo prova incontestável da morte nos casos de moribundos. Essa Lei foi regulamentada pelo Decreto $n^{\circ} 879 / 93$, que apontou a morte encefálica como uma das formas para se detectar o óbito. Para fins de expressar o consentimento na doação, conforme dispunha seu Art. $3^{\circ}$, exigia-se: I) manifestação expressa do doador ainda em vida, em documento pessoal ou oficial; II) de outro modo, na ausência de referido documento, autorizava-se, após a morte, a retirada de órgãos do dispoente, caso o cônjuge, ascendente ou descendente não a obstassem (BRASIL, 1992). Assim, previa, tal como na Lei 4.280/63, modalidade tácita (ou presumida) de consentimento.

Pouco tempo depois foi editada a Lei $\mathrm{n}^{\circ}$ 9.434/97, inovadora em diversos aspectos, mormente quanto à coleta de órgãos, tecidos e partes do corpo humano. Esta lei veio mais detalhada, e segue sendo a atual legislação em vigor a respeito do tema, regulamentada pelo Decreto $\mathrm{n}^{\mathrm{o}}$ 2.268/97, que criou o Sistema Nacional de Transplantes - STN, entidade responsável pelo processo de captação e distribuição de tecidos, órgãos e partes retirados do corpo humano para finalidades terapêuticas.

Quando de sua edição, o Capítulo II (DA DISPOSIÇÃO POST MORTEM DE TECIDOS, ÓRGÃOS E PARTES DO CORPO HUMANO PARA FINS DE TRANSPLANTE) trouxe em seu Art. 4": "Salvo manifestação de vontade em contrário, nos termos desta lei, presume-se autorizada a doação de tecidos, órgãos ou partes do corpo humano, para finalidades de transplantes ou terapêuticas post mortem" (BRASIL, 1997).

Ademais, os parágrafos do Art $4^{\circ}$, do $1^{\circ}$ ao $5^{\circ}$, dispunham sobre o procedimento de registro em documentos oficiais da pessoa não doadora, nos seguintes termos:

$\S 1^{\circ}$ A expressão "não-doador de órgãos e tecidos" deverá ser gravada, de forma indelével e inviolável, na Carteira de Identidade Civil e na Carteira Nacional de Habilitação da pessoa que optar por essa condição. 
$\S 2^{\circ}$ A gravação de que trata este artigo será obrigatória em todo o território nacional a todos os órgãos de identificação civil e departamentos de trânsito, decorridos trinta dias da publicação desta Lei.

$\S 3^{\circ} \mathrm{O}$ portador de Carteira de Identidade Civil ou de Carteira Nacional de Habilitação emitidas até a data a que se refere o parágrafo anterior poderá manifestar sua vontade de não doar tecidos, órgãos ou partes do corpo após a morte, comparecendo ao órgão oficial de identificação civil ou departamento de trânsito e procedendo à gravação da expressão "não-doador de órgãos e tecidos".

$\S 4^{\circ} \mathrm{A}$ manifestação de vontade feita na Carteira de Identidade Civil ou na Carteira Nacional de Habilitação poderá ser reformulada a qualquer momento, registrando-se, no documento, a nova declaração de vontade.

$\S 5^{\circ}$ No caso de dois ou mais documentos legalmente válidos com opções diferentes, quanto à condição de doador ou não, do morto, prevalecerá aquele cuja emissão for mais recente. (BRASIL, 1997).

Portanto, percebe-se que a redação original da Lei $n^{\circ}$. 9.434/97 trazia a presunção de autorização tácita do doador em seu caput, ressalvada a manifestação de vontade em contrário, a ser gravada em documento oficial de forma indelével e inviolável: na Carteira de Identidade Civil e na Carteira Nacional de Habilitação.

Assim, salvo as vedações legais, tais quais a vontade manifestada pelo doador em sentido contrário; a remoção de órgãos, tecidos ou partes do corpo de pessoa não identificada (Art. $6^{\circ}$, da Lei 9.434/97) ou o caso do incapaz sem consentimento de seus responsáveis legais (Art. $5^{\circ}$, da Lei 9.434/97), todo brasileiro com capacidade jurídica era presumidamente um doador em potencial, posto que a presunção realizava uma espécie de "retirada compulsória de órgãos e tecidos" (DINIZ, 2011, p. 381). Entretanto, esse dispositivo seria alterado.

\section{A ATUAL SISTEMÁTICA DESDE A LEI Nº 10.211/2001}

A modificação dos dispositivos originais da Lei. n. ${ }^{\circ}$ 9.434/97 ocorreu no ano seguinte a sua publicação por meio de Medida Provisória (MP), reeditada sucessivamente até a edição da MP 1.959-27, que traria pela primeira vez a redação atual do Art. $4^{\circ}$, e que, após ainda outras tantas MPs, seria convertida na Lei n. ${ }^{\circ} 10.211 / 2001$, alterando a Lei n. ${ }^{\circ}$ 9.434/97. O consentimento para doação post mortem deixou de ser presumido. O consentimento dos familiares, independente da expressa manifestação do doador ainda em vida, tornou-se obrigatório para o procedimento de retirada de tecidos, órgãos e partes para transplantes, conforme a nova redação do Art. $4^{\circ}$ da referida Lei, in verbis: 
Art. $4^{\circ}$ - A retirada de tecidos, órgãos e partes do corpo de pessoas falecidas para transplantes ou outra finalidade terapêutica, dependerá da autorização do cônjuge ou parente, maior de idade, obedecida a linha sucessória, reta ou colateral, até o segundo grau inclusive, firmada em documento subscrito por duas testemunhas presentes à verificação da morte (BRASIL, 1997).

Para a Professora Maria Helena Diniz, a presunção primeiramente estabelecida à favor da doação poderia resultar em mácula ao direito à privacidade, casos de ilegalidade ("máfia dos órgãos") ou até discriminação dos não doadores (DINIZ, 2011, pp. 395-405), na esteira dos que temem a ocorrência de outros atos de má-fé ou crimes, como diagnósticos fraudulentos, homicídios, eutanásia ou quaisquer outros atentados à vida que visem suprir o mercado de órgãos - o que é vedado constitucionalmente e criminalizado pela Lei 9.434/97.

Não obstante, tais medos não parecem justificar-se integralmente, vez que a própria legislação traz outras medidas na aparente tentativa de combater este comércio humano, tal qual a persecução criminal de forma repressiva, assim como outras determinações de forma preventiva. É o caso, por exemplo, do Art. $3^{\circ}, \S 3^{\circ}$, da Lei 9.434/97, que dispõe que: "Será admitida a presença de médico de confiança da família do falecido no ato da comprovação e atestação da morte encefálica". Com similar intuito, houve a proibição de doação post mortem de pessoas não identificadas (Art. $6^{\circ}$ ); assim como se precaveu a lei em investigar quaisquer suspeitas, conforme conteúdo do Art. $7^{\circ}$, parágrafo único, ao dispor que: no caso de morte sem assistência médica, por causa mal definida ou em situações nas quais seja preciso verificar a causa médica da morte, a remoção de material humano para transplantes só poderá ser realizada após a autorização do patologista responsável pela investigação e citada em relatório de necropsia (BRASIL, 1997).

Vale lembrar ainda, que a retirada de tecidos, órgãos e partes no corpo de pessoas não pode ser realizada pela mesma equipe que constatou a morte encefálica (Art. 16, $\S 3^{\circ}$, Decreto 2.268/97) - outra precaução legal, de forma a deixar o processo mais transparente. Ademais, o STN conta com uma lista única nacional de receptores, (Art. $4^{\circ}$, III, Decreto 2.268/97), regulamentada pela Portaria GM/MS n. ${ }^{\circ}$ 2.600, de 21 de Outubro de 2009, do Ministério da Saúde (BRASIL, 2009) - o que significa que eventual crime na tentativa de captar órgão, tecido ou parte de corpo humano para doação beneficiaria o próximo na lista de espera 
nacional, e não outra pessoa indicada de modo particular. ${ }^{7}$ Essa sistemática pode ajudar na diminuição das probabilidades da ocorrência desses tipos de fraudes criminosas.

Ademais, a nova redação do Art. $4^{\circ}$, trazida pela Lei 10.211/2001, ressalvava a opção feita em vida pelo doador, fazendo valer sua autonomia vontade, nos seguintes termos: "Parágrafo único. A retirada de tecidos, órgãos e partes do corpo de pessoas falecidas poderá ser realizada a partir de registro feito em vida, pelo de cujus, nos termos do regulamento". Sem embargo, tal dispositivo foi vetado pela Presidência da República pelas seguintes razões:

A inserção deste parágrafo induz o entendimento que, uma vez o potencial doador tenha registrado em vida a vontade de doação de órgãos, esta manifestação em si só seria suficiente como autorização para a retirada dos órgãos. Isto além de contrariar o disposto no caput do art. 4o - a autorização familiar, contraria a prática da totalidade das equipes transplantadoras do País, que sempre consultam os familiares (mesmo na existência de documento com manifestação positiva de vontade do potencial doador) e somente retiram os órgãos se estes, formalmente, autorizarem a doação. (BRASIL, 2001).

Destarte, a redação conferida pela Lei 10.211/2001 ao Art. $4^{\mathrm{o}}$, não só inverteu o paradigma da presunção de doação de órgãos, tecidos e partes do corpo post mortem em relação à sua concepção original; como submeteu toda possibilidade doacional ao crivo da família, obedecida a linha sucessória. Por isso ofende o direito à autodeterminação do doador, já que o consentimento para a disposição corporal com finalidades terapêuticas se origina justamente da possibilidade de autodeterminação em relação ao próprio corpo que dispõe o indivíduo, sendo irrenunciável enquanto direito fundamental (GEIDEL, 2000, p. 140).

\section{A DOAÇÃO POST MORTEM NO ESTADO DEMOCRÁTICO: LIBERALIDADE} FAMILIAR, AUTODETERMINAÇÃO INDIVIDUAL E SOLIDARIEDADE SOCIAL

O sistema vigente anterior era o da oposição (opting out system) ou do consentimento presumido (presumed consent), adotado em países como Áustria, Dinamarca, Suécia, Bélgica,

\footnotetext{
7 A principal característica das listas é que elas não funcionam por ordem de chegada, em que o primeiro a se inscrever receberá o órgão antes do segundo e assim consecutivamente. Os critérios obedecem a condições médicas, sob três fatores determinantes: compatibilidade dos grupos sanguíneos, tempo de espera e gravidade da doença. Assim, se pela ordem de chegada o primeiro colocado na fila é uma pessoa com tipo sanguíneo A e um órgão de um doador tipo B fica disponível, a primeira colocada não vai receber o transplante. De igual modo, a gravidade do estado de saúde do paciente é mais determinante que o tempo de espera - portanto, pacientes com maior risco de morte têm a preferência. (BRASIL. Governo do Brasil. Saúde. Saiba quais são os critérios da lista de espera por transplantes. 2016). Disponível em: $<$ http://www.brasil.gov.br/saude/2016/09/saiba-quaissao-os-criterios-da-lista-de-espera-por-transplantes $>$. Acesso em: $<05 / 10 / 2017>$.
} 
Austrália, França e etc., em que a lei presume o consentimento do doador mas lhe faculta a possibilidade de opor-se à tal presunção (DINIZ, 2011, p. 378).

Para Maria Helena Diniz, o consentimento presumido não se coaduna com um Estado Democrático, já que os direitos individuais e a propriedade do cidadão devem ser respeitados enquanto não atinjam os interesses da coletividade. A presunção do consentimento estatizaria o corpo, tornando-o coisa comunitária, em desrespeito aos direitos individuais do cidadão. Além disso, como a doação deve partir de um ato altruísta, de livre manifestação de vontade, uma presunção derivada do silêncio em nada transpareceria a solidariedade humana (DINIZ, 2011, pp.380-381). Assim, uma das justificativas jurídicas dada à inversão da sistemática anterior encontra guarida na defesa dos direitos de personalidade do doador, conforme pensamento ilustrado pela referida autora:

O direito de dispor, a título gratuito, do cadáver para fins lícitos pertence à própria pessoa ou aos seus familiares. Se o cadáver é um resíduo da personalidade, se é coisa extra commercium, a que têm direito seus parentes, que dele poderão dispor gratuitamente e exigir o seu devido respeito, evitando qualquer profanação, poderia haver disposição legal instaurando, na seara jurídica, a doação presumida post mortem, de órgão e tecido humano para fins de tratamento ou transplante? Por tais razões merece aplausos a nova redação do Art. $4^{\circ}$ da Lei n. 9.434/97, dada pela Lei n. 10.211/2001, não mais acatando a doação presumida de órgãos. (2011, p. 396).

Segundo Beauchamp e Childress, a autonomia na ética biomédica contemporânea se refere àquilo que uma pessoa faz com sua própria vida, i.e. ao fato de que sua existência é moldada por escolhas pessoais (2011, p. 74). Quando se pensa, nesse mesmo contexto, em ética enquanto direito, a referencia se volta para o individualismo liberal, pelo qual no interior de uma sociedade deve-se criar espaços para que o indivíduo desenvolva seus projetos pessoais, fundamentados em suas liberdades. (2011, pp. 80-90). É sobre essa autonomia da ética individualista, essa autodeterminação individual, que se sustenta os direitos de personalidade (GARCIA, 2007, pp. 75-87) - direitos fundamentais do indivíduo.

No entanto, de volta a questão da doação, com a supressão do consentimento presumido pela sistemática que impõe o consentimento familiar sob a justificativa de defesa dos direitos de personalidade do doador, não haveria ao contrário, mormente com o veto do parágrafo único na nova redação do Art. $4^{\circ}$, trazida pela Lei n. 10.211/2001, uma supressão da autonomia do individuo? Como poderia a vontade da família suprimir a vontade do doador a respeito da disposição do próprio corpo, quando houve manifestação em vida? Considerando 
que a proteção da personalidade post mortem é conferida em respeito ao próprio titular do direito de personalidade, i.e., ao morto (GARCIA, 2007, pp. 107-108), a resposta é que não poderia haver tal supressão, sob pena de se macular a autodeterminação do falecido.

Ademais, no ano seguinte a promulgação da lei 10.211/2001 teve início o Novo Código Civil (2002), que dispôs logo em seu início, a respeito dos direitos de personalidade, o seguinte conteúdo: “Art. 14. É válida, com objetivo científico, ou altruístico, a disposição gratuita do próprio corpo, no todo ou em parte, para depois da morte". Assim, diante de lei posterior, deveria restar superada a noção de que o consentimento familiar é absoluto (lex posterior derrogat priori), valendo para os fins de doação post mortem a disposição do doador realizada em vida, mediante documentos comprovando sua vontade manifesta. Foi justamente essa a interpretação dada ao referido artigo pelo Enunciado 277 do Conselho da Justiça Federal (CJF), na IV Jornada de Direito Civil, in verbis:

O art. 14 do Código Civil, ao afirmar a validade da disposição gratuita do próprio corpo, com objetivo científico ou altruístico, para depois da morte, determinou que a manifestação expressa do doador de órgãos em vida prevalece sobre a vontade dos familiares, portanto, a aplicação do art. $4^{\circ}$ da Lei n. 9.434/97 ficou restrita à hipótese de silêncio do potencial doador. (BRASIL, 2016).

Do ponto de vista de um Estado Social de Direito, o cadáver seria disposto como res communitatis, de modo que a doação presumida impor-se-ia objetivando o bem comum. Essa concepção da doação se liga à bioética pelos princípios da solidariedade e da socialidade. $\mathrm{O}$ princípio da socialidade impõe a cada cidadão considerar a própria vida e a do outro como um bem pessoal e social, pois entende que a vida e saúde de cada um dependem da do outro, como se evidencia em claros exemplos de poluição ou epidemia; além disso, apoiando-se na ideia de justiça social, o princípio também obriga a comunidade a promover o bem comum pela promoção do bem, da vida e saúde de cada membro, garantindo-se o acesso aos tratamentos necessários, ainda que a custo dos que estão bem - exemplo, é o financiamento coletivo da saúde através de impostos (SGRECCIA, 2009, p. 181).

Mas até a prática da doação presumida não obstaria a possibilidade de manifestação de vontade do doador (ou ainda de sua família) em sentido contrário, ao passo que tornaria mais fácil a realização de transplantes, embasando e promovendo a solidariedade entre os cidadãos (fundamento da República, conforme dispõe o Art. $3^{\circ}$, I, da Constituição Federal):

Não há dúvida de que uma norma que atribua valor legal positivo ao silêncio do defunto levaria a considerar o cadáver como res communitatis, embora no 
respeito dos limites ditados pela confissão religiosa a que pertence o sujeito ou pelas suas convicções pessoais.

Em todo caso, embora em linha de princípio o silêncio-assentimento possa ser aceito, a sua admissibilidade deve, todavia, encontrar um duplo limite. De um lado, com efeito, deve-se garantir o respeito das escolhas religiosas ou pessoais, oferecendo-lhes todas as informações necessárias para que ele, se julgar oportuno, possa recusar o próprio consentimento à retirada. Do outro lado, é necessária uma vasta obra de sensibilização da opinião pública que sirva para difusão de nova uma cultura, de modo que a doação de órgãos se torne cada vez mais um ato espontâneo (SGRECCIA, 2009, p. 667).

Nem todos compartilham do conteúdo ético do corpo enquanto coisa comunitária, pois, ainda que seja res e não mais persona, ele conserva sua referência fenomenológica e psicológica para os sobreviventes. Daí porque, argumenta Sgreccia (2009, pp. 672-673), o bem comum não pode excluir totalmente o respeito à própria vontade do indivíduo e dos sobreviventes, que mantém também um peso de ordem ética - o consentimento esclarecido é um dos princípios basilares que definem o problema ético dos transplantes.

Portanto, quando se critica a absoluta liberalidade familiar não se está a ignorar os direitos de personalidade ou a autodeterminação do indivíduo, mas justamente ao contrário: trata-se de efetivá-la, fazendo valer sua real vontade e autonomia, seja ela no sentido doacional ou não. Quanto ao melhor caminho a essa realização, parece que uma boa opção seria ofertar diversas oportunidades para o doador, ao longo da vida, manifestar-se a respeito do tema, além de se buscar promover a solidariedade ética (e não meramente normativa) entre as pessoas através da sensibilização da opinião pública, para que a doação de órgãos se torne cada vez mais espontânea - entretanto, maiores conclusões caberão a estudos posteriores.

Por fim, em um Estado Democrático de Direito, os direitos sociais e individuais (e também os direitos coletivos) se limitam e se integram mutuamente, visando a mais ampla proteção dos direitos fundamentais, em suas três dimensões (ou gerações), constituindo o fundamento completo da dignidade humana. Significa dizer, conforme aponta Ranieri (2013, pp. 317-319), e em sentido similar Dalmo de Abreu Dallari (2005, pp. 307-310), que não há disponibilidade sobre nenhum direito fundamental (assim como também não o há quanto ao regime democrático, separação de poderes e etc.), os quais, acrescente-se, devem ser 
harmonizados. ${ }^{8}$ E é esse o sentido que deve ser atribuído aqui ao Estado Democrático de Direito brasileiro. Assim, no passo dessa lógica conciliatória entre direitos fundamentais, o respeito aos postulados deve se afastar dos extremos - da exclusão total ou da absoluta necessidade de intervenção familiar no caso de doação post-mortem:

[...] la ponderación se impone por exigencias del buen sentido. La mayor entidad y la más básica fundamentación de la causa de la extracción (transplante ad vitam) inclinarán la balanza de la justicia en favor de ésta, aligerando en su ponderación relativa la atendibilidad de la pietas familiar. Igualmente, la menor significación de la manipulación del cadáver respecto de sus honras fúnebres hace decrecer la razón de lesividade de la misma desde el punto de vista del sentimiento familiar de la pietas $\mathrm{y}$, consiguientemente, la razón de atendibilidad de la voluntad de los allegados. He aqui, en sustância, los elementos a valorar y ponderar. En función de las distintas formas de su conjugación en la realidad de los casos deberán adoptarse modalidades proporcionales de exigencia y de regulación. Dos extremos nos parecen igualmente evitables: el de la generalización absoluta de la necesidad de intervención de los familiares en aras de la pietas y del Totensorgerecht, y el contrario, de la absoluta y generalizada exclusión de los mismos (CAÑAS, 1987. pp. 94-95).

Necessário ainda recordar que a concretização do direito à vida e à saúde, enquanto direitos à prestação, no que se refere aos transplantes de órgãos, não pode se dar pela possibilidade de compulsão do Estado em fornecer tais materiais humanos (o que, quiçá, poderá ser futuramente superado com o avanço da tecnologia e da biociência), mas sim em relação ao direito à organização e ao procedimento dos sistemas inerentes a construção das políticas públicas que fundamentam e propiciam sua efetivação - para além das normas penais que já cumprem sua função ao vedar a mercantilização de material humano.

Destarte, na incumbência da função de direito à prestação jurídica, o direito à organização e ao procedimento compõe o núcleo do direito social à saúde, não só em sua estruturação, mas também na interpretação dessas normas (de organização e procedimento), que devem ser interpretadas de acordo com os direitos fundamentais que a justificam (MENDES; BRANCO; 2011, p. 181). Nesse sentido, a legislação que organiza a doação de órgãos post mortem deve ser estruturada de modo a coadunar-se com um Estado Democrático de Direito. Sem embargo, enquanto não sobrevier alteração legislativa, em caso de análise

\footnotetext{
8 Trata-se do princípio de interpretação constitucional da harmonização ou da concordância prática, segundo o qual os bens jurídicos constitucionais possuem igual valor, de modo que, em eventual colisão entre direitos fundamentais (ou bens jurídicos constitucionalmente protegidos), não se pode sacrificar totalmente um deles em detrimento de outro para solucionar o conflito. Assim, é preciso que se estabeleçam limites entre eles, condicionando-os reciprocamente de modo a harmonizá-los e obter a concordância prática. (CANOTILHO, José Joaquim Gomes. Direito constitucional e teoria da Constituição. $7^{\text {a }}$ Ed. Coimbra: Almedina, 2003. p. 1225).
} 
judicial, deveria a mesma ser orientada conforme a Constituição $0^{9}$ no sentido de se interpretar a redação do Art. $4^{\text {o }}$, da Lei n. 9.434/97 (sem alterar o texto) da seguinte forma:

Salvo vontade manifestada e documentada pelo doador em vida, a retirada de tecidos, órgãos e partes do corpo de pessoas falecidas para transplantes ou outra finalidade terapêutica, dependerá da autorização do cônjuge ou parente, maior de idade, obedecida a linha sucessória, reta ou colateral, até o segundo grau inclusive, firmada em documento subscrito por duas testemunhas presentes à verificação da morte.

Esse entendimento encerraria no mínimo um meio termo, apto, parece seguro dizer, a realizar os ditames de um Estado Democrático de Direito, tal qual almejado pela Constituição Federal, no sentido de conciliar os preceitos constitucionais fundamentais, protegendo e garantindo os direitos individuais (como os direitos de personalidade) em toda sua autonomia; mas sem olvidar os parâmetros que orientam os direitos sociais, garantindo-se, por fim, a dignidade da pessoa humana em sua totalidade, ao conciliar os direitos de individuais com o princípio da solidariedade que fundamenta os direitos sociais, o que poderia - ao menos em tese - maximizar a organização e o procedimento das políticas públicas de doação de órgãos a partir de seu pilar normativo, conferindo-lhes maior eficiência na concretização dos direitos fundamentais à vida e à saúde, quando dependentes de doação de órgãos.

\section{CONSIDERAÇÕES FINAIS}

As legislações brasileiras pretéritas sobre doação de órgãos post mortem apostavam no sistema do consentimento presumido, e nesse sentido, induziam à maximização (ao menos do ponto de vista teórico) do potencial de transplante de órgãos em prol da coletividade característica que enaltecia a ideia de um Estado Social de Direto.

Já a atual legislação do tema, enquadrada na Lei n. 9.434/97, modificada pela Lei n. $10.211 / 2001$, tentou dar primazia ao viés individual, fazendo prevalecer a vontade dos

\footnotetext{
9 O princípio da interpretação conforme a Constituição abriga, simultaneamente, uma técnica de interpretação e um mecanismo de controle de constitucionalidade. Como técnica de interpretação, o princípio impõe ao judiciário que interprete a legislação de modo a realizar mais adequadamente os valores e fins constitucionais. Assim, dentre as interpretações possíveis, deve-se optar por aquela que apresenta mais afinidade com a Constituição. Já como instrumento de controle de constitucionalidade, o princípio permite ao intérprete, mormente a Suprema Corte, preservar a validade de uma lei que, na sua leitura mais óbvia, seria inconstitucional. Nessa hipótese, o judiciário, simultaneamente, declara inconstitucional determinada interpretação, ao passo que afirma outra como sendo a mais compatível com a Constituição. (BARROSO, Luís Roberto. Curso de Direito Constitucional Contemporâneo: os conceitos fundamentais e a construção do novo modelo. $5^{\text {a }}$ Ed. São Paulo: Saraiva, 2015. pp. 336-337).
} 
familiares - inclusive, paradoxalmente, sobre a própria manifestação de vontade do doador o que poderia comprometer a eficiência das políticas públicas de doação de órgãos e enfraquecer o laço da solidariedade sob o qual se fundam as políticas sociais, dado que uma das bases a sustentar as políticas públicas está em sua organização normativa.

Dessa maneira, em respeito à harmonização dos postulados constitucionais sociais e individuais que norteiam um Estado Democrático de Direito, não há sentido em não se fazer a vontade daquele que expressa, de forma inequívoca, a vontade de ser doador, e de ajudar aos outros no caso de seu falecimento, consagrando o princípio da solidariedade e da socialidade ao poder salvar ou melhorar qualitativamente a vida de várias pessoas - ainda que seus familiares, contrariamente, tenham interesse em preservar todos os seus restos mortais. Significa dizer, a liberalidade familiar só deveria se dar de modo subsidiário, no caso de ausência, por parte do falecido, de manifestação expressa em vida de fazer-se ou não doador o que, ademais, estaria de acordo com o princípio bioético do consentimento esclarecido.

Entretanto, enquanto não sobrevier qualquer alteração legislativa (pois via hermenêutica deverá prevalecer o Enunciado 277 do CJF), o trabalho para a melhora da eficiência das políticas públicas de doação de órgãos passa pela conscientização da importância da doação de órgãos e a existência de profissionais qualificados para tratar com os familiares no momento de extrema dor, sendo certo que a melhora da eficiência da doação poderá evitar dor semelhante de outrem, fortalecendo os laços de solidariedade social.

\section{REFERÊNCIAS}

BARROSO, Luís Roberto. Curso de Direito Constitucional Contemporâneo: os conceitos

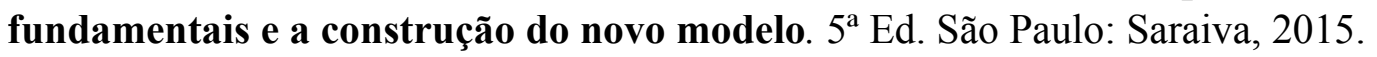

BERLINGUER, Giovanni; GARRAFA, Volnei. O mercado humano: estudo bioético de compra e venda de partes do corpo. $2^{\text {a }}$ Ed. Brasília: Universidade de Brasília, 2001.

BEAUCHAMP, Tom L.; CHILDRESS, James F. Princípios de Ética Biomédica. Trad.: Luciana Pudenzi. 2a Ed. São Paulo: Edições Loyola Jesuítas, 2011.

BRASIL. CONSELHO DE JUSTIÇA FEDERAL. Enunciado 277. 2016. Disponível em: $<$ http://www.cjf.jus.br/enunciados/enunciado/227>. Acesso em: 28/02/2018. 
. Constituição Federal da República dos Estados Unidos do Brasil, de 1934. Diário Oficial da União. 16, Jul. de 1934. Disponível em: < $\underline{\text { http://www.planalto.gov.br/ccivil 03/ }}$ constituicao/constituicao34.htm $>$. Acesso em: $<30 / 09 / 2017>$.

. Constituição da República Federativa do Brasil, de 1988. Diário Oficial da União. Brasília, DF, 5, Out. de 1988.

. Lei 4.280, de 6 de Novembro de 1963. Dispõe sôbre a extirpação de órgão ou tecido de pessoa falecida. Diário Oficial da União. Brasília, DF, 11, Nov. de 1963. Disponível em: <http://www.planalto.gov.br/ccivil_03/leis/1950-1969/L4280.htm>. Acesso em: $<26 / 09 / 2017>$

Lei 5.479, de 10 de Agosto de 1968. Dispõe sôbre a retirada e transplante de tecidos, órgãos e partes de cadáver para finalidade terapêutica e científica, e dá outras providências. Diário Oficial da União. Brasília, DF, 14, Ago. de 1968. Disponível em: $<$ http://www.planalto.gov.br/ccivil_03/leis/1950-1969/L5479.htm $>$. Acesso em: $<26 / 09 / 2017>$.

. Lei 8.489, de 18 de Novembro de 1992. Dispõe sobre a retirada e transplante de tecidos, órgãos e partes do corpo humano, com fins terapêuticos e científicos e dá outras providências. Diário Oficial da União. Brasília, DF, 19, Nov. de 1992. Disponível em:

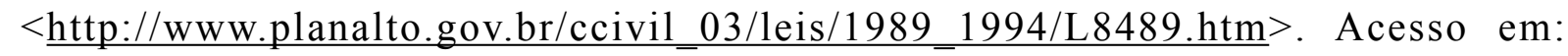
$<26 / 09 / 2017>$.

. Lei 9.434, de 4 de Fevereiro de 1997. Dispõe sobre a remoção de órgãos, tecidos e partes do corpo humano para fins de transplante e tratamento e dá outras providências. Diário Oficial da União. Brasília, DF, 5, Fev. de 1997. Disponível em: $<$ http://www.planalto.gov.br/ ccivil_03/leis/L9434.htm>. Acesso em: $<27 / 09 / 2017>$.

Governo do Brasil. Saúde. Saiba quais são os critérios da lista de espera por transplantes. 2016. Disponível em: <http://www.brasil.gov.br/saude/2016/09/saiba-quais-

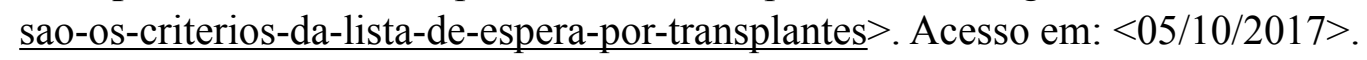

. PRESIDÊNCIA DA REPÚBLICA. CASA CIVIL. SUBCHEFIA PARA ASSUNTOS JURÍDICOS. Diário Oficial da União. Brasília, DF, 24, Mar. de 2001. Mensagem No 252, de 23 de Março de 2001. Disponível em: < http://www.planalto.gov.br/ ccivil_03/leis/Mensagem_Veto/2001/Mv252-01.htm>. Acesso em: $<05 / 10 / 2017>$.

. PRESIDÊNCIA DA REPÚBLICA. MINISTÉRIO DA SAÚDE. Portaria GM/MS 2.600, de 21 de Outubro de 2009. Aprova o Regulamento Técnico do Sistema Nacional de Transplantes. Diário Oficial da União. Brasília, DF, 21, Out. de 2009. Disponível em:

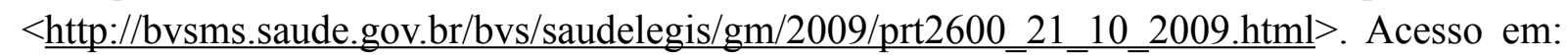
$<05 / 10 / 2017>$.

BUCCI, Maria Paula Dallari (org.). O conceito de política pública em direito. In: Políticas Públicas: reflexões sobre o conceito jurídico. São Paulo: 2006.

públicas. São Paulo: Saraiva, 2013.

Fundamentos para uma teoria jurídica das políticas 
CANOTILHO, José Joaquim Gomes. Direito constitucional e teoria da Constituição. $7^{\mathrm{a}}$ Ed. Coimbra: Almedina, 2003.

CAÑAS, Antonio Gordillo. Transplantes de órganos: <<pietas>> familiar y solidariedade humana. Madrid: Editorial Civitas, 1987.

DALlARI, Dalmo de Abreu. Elementos de Teoria Geral do Estado. $25^{\text {a }}$ Ed. São Paulo: Saraiva, 2005.

DINIZ, Maria Helena. O estado atual do biodireito. $9^{\text {a }}$. ed. rev., aum. e atual. São Paulo: Saraiva, 2014.

GABARDO, Emerson. A eficiência no desenvolvimento do Estado brasileiro: uma questão política e administrativa. In: MARRARA, Thiago. (Org.). Princípios de Direito Administrativo: legalidade, segurança jurídica, impessoalidade, publicidade, motivação, eficiência, moralidade, razoabilidade, interesse público. São Paulo: Atlas, 2012.

GARCIA, Enéas Costa. Direito Geral da Personalidade no Sistema Jurídico Brasileiro. São Paulo: Editora Juarez de Oliveira, 2007.

GEDIEL, José Antonio Peres. Os transplantes de órgãos e tecidos e a invenção moderna do corpo. Curitiba: Moinho do Verbo, 2000.

LASWELL, Harold D. Politics: Who Gets What, When, How. New York: Peter Smith, 1950.

LIMA, Cíntia Rosa Pereira. O Valor do Corpo e as Leis de Mercado. Revista da Faculdade de Direito, Universidade de São Paulo. São Paulo, v. 106/107, p. 159-178, jan./dez. $2011 / 2012$.

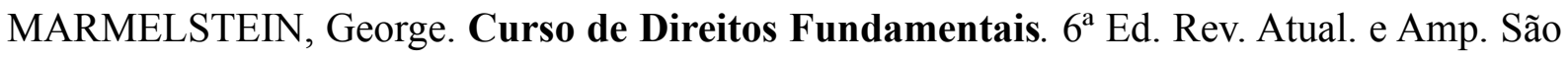
Paulo: Atlas, 2016.

MENDES, Gilmar Ferreira. BRANCO, Paulo Gustavo Gonet. Curso de Direito Constitucional. 6 ${ }^{a}$ Ed. Rev. e Atual. São Paulo: Saraiva, 2011.

OLSEN, Ana Carolina Lopes. Direitos Fundamentais Sociais: Efetividade Frente à Reserva do Possível. $1^{a}$ Ed. Curitiba: Juruá, 2008.

RANIERI, Nina Beatriz Stocco. Teoria do Estado: do Estado de Direito ao Estado Democrático de Direito. Barueri: Manole, 2013.

SAMPAIO, Marcos. O Conteúdo essencial dos direitos sociais. São Paulo: Saraiva, 2013.

SARLET, Ingo Wolfgang. A eficácia dos direitos fundamentais: uma teoria geral dos direitos fundamentais na perspectiva constitucional. $11^{\mathrm{a}} \mathrm{Ed}$. Rev. e Atual. Porto Alegre: Livraria do Advogado, 2012.

SILVA, José Afonso da. Aplicabilidade das Normas Constitucionais. $8^{\text {a }}$ Ed. São Paulo: Editora Malheiros, 2012. 
Malheiros, 2013.

.Curso de Direito Constitucional Positivo. $36^{\circ}$ Ed. São Paulo:

SGRECCIA, Elio. Manual de Bioética. Fundamentos e ética biomédica I. Trad.: Orlando Soares Moreira. $3^{\text {a }}$ Ed. Rev. e atual. São Paulo: Edições Loyola, 2009.

SMANIO, Gianpaolo Poggio. Cidadania e Políticas Públicas. In: SMANIO, Gianpaolo Poggio; BERTOLIN, Patrícia Tuma Martins; BRASIL, Patricia Cristina. (Org.) O Direito na Fronteira das Políticas Públicas. São Paulo: Páginas \& Letras Editora e Gráfica, 2015.

TORRES, Marcelo Douglas de Figueiredo. Estado, democracia e administração pública no Brasil. Rio de Janeiro: Fundação Getúlio Vargas, 2004. 